Military Technical College Kobry El-Kobbah, Cairo, Egypt

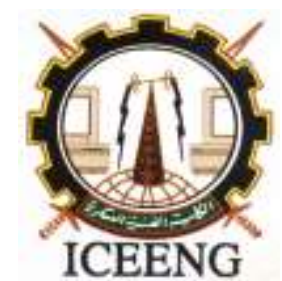

\author{
$11^{\text {th }}$ International Conference \\ on Electrical Engineering \\ ICEENG 2018
}

\title{
ADVANCED LOW-COST SMART POWER SAVING SYSTEM FOR BUBLIC BUILDINGS
}

\author{
F. Selim*, and Mohamed I. Abdelwanis*
}

\begin{abstract}
This study reviews the problem of energy consumption reduction in public buildings in Egypt in the period 2005 up to 2016. The public buildings in Egypt consume around 30\% of the total electrical energy. A considerable portion of consumed power is wasted unnecessarily by continuous operation of electrical loads such as fans and lights even without imperative need for these loads especially in public buildings(e.g. Auditoriums, Shopping malls and Theatres). The wasted amount of electrical energy necessitates searching for possible means to save operating cost. In this study, a proposed framework based on a low cost smart controlled power saving system is implemented to control the usage of electrical energy. The idea is to use a low cost smart system to control the power input to the lighting and non-emergency equipment in governmental buildings during unworking hours started at $4 \mathrm{PM}$ till $8 \mathrm{AM}$. The proposed power saving system is designed with efficient controllers to regulate the on-off operation of electrical devices during the un-work shift from 4 PM to 8 AM "night guard work-shift". Two measures are carried out in this shift, which are the total accumulation times during OFF periods and the total accumulation times during $\mathrm{ON}$ periods of electrical equipment. The assessment of the proposed system is based on the savings ratios for certain energy consumption. The main advantages of proposed power saving system in comparison with the existing methods are the low cost of its implementation and the highest power consumption level achieved. The outcome of this study is to increase the energy saving from the minimum value, i.e. about $125.84 \mathrm{GWh}(0.08 \%$ of total consumed energy) to the largest possible value, i.e. 3523.52 GWh $(2.268 \%$ of total consumed energy) which can save money between 90.6048 million pounds, as a minimum value, to about 2536.9 million pounds yearly.
\end{abstract}

KEYWORDS Public buildings, Power saving, Smart metering, Controlled systems.

* DEpt. electrical power and machines, Faculty of Engineering, Kafr Elshiekh University. 


\section{Survey of Power Saving Procedure}

Numerous researches have analysed how to develop a building energy consumption to enhance energy efficiency, where each research has its own active and passive points in solving the waste useful consumed energy in public buildings (methods of saving power). In [1], a proposed technique, the Energy-Aware Framework (EAF), is introduced to manage and control power status of various Consumer Electronic (CE) devices operating throughout the home. The proposed framework is composed of a power management scheme to control power consumptions of devices according to the classified service categories. The authors in [2] introduced a strategy to saving power compared to conventional system. In this paper, the authors developed a low voltage dc lighting system (LVDC) with LED luminaires and wireless sensor network control. With the proposed smart lighting system, the ambient light at the user's location is able to be controlled in real-time to give users the most amount of indoor environmental quality but in an efficient manner of energy. Also, wireless lighting sensors are used to realize better energy conservation and the human interaction with the indoor lighting system by dimming LED lighting according to set points in the controller. In [3], a proposed smart energy saving system (IESS) is introduced that automatically blocks standby power. The proposed "co-operation-based power control algorithm" can significantly save standby power using the hierarchical relationship between home appliances. It can also simultaneously minimize users' inconveniences and standby power, based on the users' behaviors. By this method, the costs will be reduced and system efficiency is improved by reducing response time. In [4,5], the researchers used the Passive Infrared "PIR" Sensor and MCS 51 family Microcontroller to control the total operation of equipment or appliances in general public places like auditoriums, shopping malls and theatres etc. These techniques can reduce the power wastage and human efforts. The research [6] proposed a technique to save power considering the characteristics of appliances according to their classes (reducible, deferrable, and stoppable) and their power margin by using bidirectional communications. According to authors, the technique needs to adapt the class and power margin of individual appliance to the user's convenience. Also, security in the communications may be a great concern. Another study, depending on the real time implementation of Volt-VAR control (VVC) and associated real time energy saving benefits, is presented in [7], which will empower the utilities to quickly compute the benefits of VVC implementation without having to wait for long periods of time before calculating the benefits. In [8], a proposed study of a Photovoltaic (PV) blind-integrated daylight responsive dimming system using LED lighting is introduced. It integrates a PV blind system with dimming system coordinated with daylight responsive. Thus, saving of electricity and electrical lighting energy can be achieved at the same time with moderate saving. This proposed methodology cannot be applied in each building, since it may need efficient system and professional persons for accurate applications. This system is very expensive to be applicable in all Egyptian governmental buildings. In [9, 10], the studies presented the results of a monitoring study providing some recommendations based on the human and technical aspects of Lighting Control Systems (LCS) applied for scale cases. Generally, there are three methods of saving, the first indicated that the manual switching was greatly appreciated and it accomplished good energy performances, while the second is the daylight-linked LCS that achieved low improvement. The third method is the desk lamp that achieved higher savings than the two other types. However, these 
researches need high experience and professional technical persons for proper coordination to achieve the efficient energy saving. Authors in [11] proposed installing lighting controls, which have two possible strategies. The first considers the existence of lighting control for $50 \%$ of the office facilities, reducing the operating hours that the lamps are turned on, while the second includes the total lighting control, i.e. $100 \%$ of the office facilities. The energy consumption on average was $23 \%$ for heating, $20 \%$ for cooling, and $46 \%$ for lighting, showing that lighting plays a significant role in the total energy demand mainly because of its large operating time. The saving in total energy using partial control achieved up to $18 \%$ reduction, while total lighting control achieved $36 \%$ saving.

In [12], a multi-objective optimization model was developed during the early planning stage to predict and optimize the building energy consumption, initial cost and carbon emission for an eco-community. With a Matlab program implementing the BIN method, the model can evaluate the energy saving potential for different types of building envelops and AC heating/cooling source technologies and calculate the energy consumption of buildings and thus, it can save energy and money.

Another study [13] in china, proposed a real-time energy consumption monitoring system that was presented for large public buildings. This is beneficial for energy saving and helps to establish consumption of the building energy performance evaluation system. The outcome is an improvement in energy consumptions with computerized system. In other words, there is another solution for saving energy through the using of net-metered PV systems with DC power appliances instead of AC appliances. The studies indicated that, a saving of about $14 \%$ can be achieved with a storage system and about $5 \%$ saving can be achieved without a storage system. It was mentioned that, an additional savings of approximately $33 \%$ would be gained by completing the current transition toward the use of DC-internal technologies to supply residential electricity demands [14]. In [15], the authors paid attention to the consumption of buildings energy since it is responsible for about $40 \%$ of total energy consumption in the European Union "EU". Thus, the reduction in buildings energy consumption represents an important component of environmental protection efforts. This paper analysed the energy consumption of 68 school buildings in Luxembourg. A separate collation of electricity and heat energy consumptions allowed making a detailed analysis of specific energy parameters then it succeeded to reduce useless consumed energy. Reference [16] presented three modified energy-savingbased indoor comfort control algorithms to yield an energy-saving decoupling indoor comfort control (ESDICC) algorithms. A simple automatic supervisory control system (ASCS) was presented to indicate that the energy saving depends upon the occupancy of place with utilizing as much as possible of the outdoor light to save electricity that would otherwise be used to turn on the lights to maintain the luminance of indoor within the normal range. Research [17] concentrates on the energy saving by using energy system analysis to perform hourly simulation of the current energy system (Danish as a case study). The Danish district heating sector introduces the combination of reductions in electricity and heat demands to show the benefits of coordinating savings in the electricity and district heating sectors (about 11.16 TWh in primary energy supply). However, in case of saving heat only, the saving is 8.19 TWh. This means that, the system that includes both electricity and heat can provide more savings. In [18], the study interested in one milk manufacturing factory in Malaysia, which faced high expenses issue on 
electricity bill. The study achieved energy savings for the industry through management of electricity consumption by the proposed programs. Through less than 3 years, on-site generation, lighting re-lamping, and solar photovoltaic system can have a potential annual savings of RM $320,603.92$. This ensures that the implementation of management of electricity consumption can help to reduce energy in dairy industry and medium enterprise sector. It is also possible to save energy in buildings, which use T5 tube lamp (the fluorescent T5 tube lamp was promoted and aimed to replace the existing fluorescent T8 tube lamp because the T5 fluorescent lamp consumes less energy than the T8 lamp) with a low class electronic ballast and a passive low-pass filter to reduce harmonics [19]. A similar study presented new trends and progressive strategies to reduce energy consumption of lighting systems. The proportion of electricity attributable to lighting is significant and not negligible in Slovakia. This research introduced a new installation with more economical costs "energy saving" and environmental friendly compared to the old one. It applied many strategies to reduce the consumed energy in lighting (replace lamps, natural lighting...etc.) [20]. Obviously, the control of day light is one of many methods to save energy in buildings. In [21], the authors showed that the energy consumption for lighting and air conditioning can be kept minimum with well-designed natural lighting "controlled by technologies or systems which guarantee accessibility from all areas inside buildings". However, there are some disadvantages presented by these systems since the thermal and lighting loads balance was inappropriate for direct application with skylight systems. In addition, light shelves affect the architectural and structural design of a building and must be considered at the start of the design phase as they require somewhat high roof in order to function efficiently, and prismatic glazing has a negligible effect when the sky is over cast...etc.

The authors were interested with the saving in consumed lighting energy in [22]. They introduced cluster analysis, unlike the general averaging approach which provides only a single representative value. They gave a group of representative values for determining the total savings of potential energy that can be obtained from the lighting systems of the buildings in the commercial sector, if a certain standard lighting power density (LPD) value is given in the building energy code. According to the simulation study, the calculated clustering results for the estimated energy savings have much smaller errors than those from the general approach in all case studies. Finally, the research in [23] deals with the problem of consumed power in building in detail. This research studies the ways of electrical energy saving in office by: (1) studying the payback period of replacing certain electric lamp with the new ones with higher technology, e.g. LED lamp, and the variation of cost, (2) studying the advantages of using individual manual lighting controls, the individual manual switch for controlling individual lights, and (3) collecting data about electrical energy consumption of any electrical appliances, e.g. lamp, air condition, computer, printer, television. The cost benefits are summarized with these energy saving methods implemented, where the manual lighting was the preferable method. From above survey, the following points can be concluded:

1. Some researches solved the wasted energy through individual solutions on place itself or special region in building such as $[4,5]$, where the saving of consumed power is based on using (PIR) Sensor and/ MCS 51 family Microcontroller for all needed saving regions. This system may be very costly to be implemented in all places, e.g. for 
building containing 100 corridors, it needs 100 saving systems, which is very expensive, and it do not include other appliances.

2. Other researches concerned with complete solutions through integrated system, which can be applied on the entire places or building. But these researches will be expensive to be applied, especially on investment buildings and they need experience and professional technical persons for coordination to achieve efficient energy saving. This research concerns with solving the problem through a generalized strategy that is valid for all buildings, either they are investment buildings or not by simple and economical proposed system "circuit" as will be shown in the next sections.

\section{Egyptian Consumed Energy}

\section{A) A review of the challenges of energy sector in Egypt:}

Energy is the basic necessity for the economic development of any country. It is practically impossible to estimate the actual magnitude of the part that energy has played in the building up of present-day civilization [24]. The building sector consumes approximately $30 \%$ of the energy produced in most countries [25-26]. This share is expected to increase continuously owing to the growth in population together with increasing demand for building services and comfort levels. In this respect, many countries have launched policies to promote energy efficiency in buildings. One type of those policies is a regulatory requirement called the building energy code. This is commonly used to control building design practice and enforce energy efficiency [27]. According to [28], the total consumed power in Egypt through 2015-2016 equals $155318 \mathrm{GWh}$, which is about $168.66 \%$ of that consumed during the year 2005-2006 as shown in Table 1 . Table 2 demonstrates the total consumed energy in government institutions, which equals to 6292 GWh (about 4.05\% from total consumed power in Egypt). This huge energy was consumed in government buildings through 24 hours per day in 2015-2016.

Due to impairment of available capacities of electricity generation by means of conventional and low renewable generation methods in Egypt, ministry of electricity and electricity networks face a problem to provide powers to all loads. Energy saving has attracted great attention as a global issue because of recent environmental problems. As a part of energy saving efforts through the recent years, governments are implementing policies that encourage the distribution of energy saving systems by many traditional methods, such as:

1- Cooperation with the Ministry of petroleum to raise the natural gas production, which used in thermal generation stations or to import natural gas to satisfy the needs.

2- Using the diesel fuel and gasoline as alternatives to natural gas.

3- Using coal in cement factories to give leading share of natural gas to generation stations.

4- Carrying out some power saving procedures, such as:

- Raising awareness among citizens about the use of electric energy savings, e.g. using the important apparatus only especially through peak hours

- Using the power saving lamps

- Using individual solar energy sources (PV)

- In some regions, the government used a load shedding strategy 
5- Trying to implement other sources of generation energy such as nuclear, wind and solar

6- Increasing the network efficiency, by decreasing the voltage drop from $14 \%$ to the lessen value [29]

7- Using power saving systems in hotels and management offices.

In this paper, the concern is directed to the last choice through proposing power saving system. Applications of the proposed saving procedure are integrated with the governmental buildings that consume around $30 \%$ of the produced energy. The proposed saving system can be applied through night guard shifts (4 PM:8 AM) and the saving power advice procedures from ministry of electricity can applied through other work shift (8 AM: 4 PM).

\section{B) Paper organization}

This paper is organized as follow: Section II presents a literature review for the energy consumption in Egypt during the period from 2005 to 2016. Also, the main merits and the paper organization are presented in section II. In section I, authors concentrate on the analysis of previous efforts on power saving procedures (other saving methods). Section III describes the features of the proposed power saving system. The assessment of the proposed saving card is presented in Section IV. Section V concludes the paper outcomes and the main merits in comparison to other techniques. This study is based on 30 references which are added at end of this study.

\section{Proposed Power Saving System}

\section{A) Proposed saving systems}

Lighting was identified as one of the major sources of energy consumption with high energy saving potentials. This information has recently been highlighted in numerous side events that took place during the United Nation Climate Change Conference [30]. According to the International Energy Agency (IEA), artificial lighting makes up 14\% of electrical consumption in the European Union and 19\% worldwide [21].

The proposed saving system forces the night guard (from 4: PM to 8 AM) to operate the electrical power apparatus (lighting, fans...etc.) according to timing check table except the emergency loads. The main objective of this proposed saving circuit is to operate the main building contactor as ON/Off switch to supply electrical power to building regions by security smart circuit. During ON time, the lighting and other unused equipment in the building are ON, while they are switched OFF during other times. For instance, if the operating timing table is to check the buildings consumed power (lighting, fans...etc.) for 15 minutes each two hours, which means that if the total shift time is 8 hours, the check operating time will be 60 minutes (4 times $\times 15$ minutes). Also, the idea of the proposed card is mixed with organization of safe-guard work indicating possible penalties of those workers with high consuming electrical energy. The power saving system have two push buttons; one "counter 1" for night guard to start his shift time with own address and OFF contactor, the other button "counter 2" to start ON contactor for check the building "contacting the power supply to various regions" as shown in Fig. 1 (except the emergency loads).

The operation of proposed power saving system can be illustrated through these steps: 
1- Computing OFF hours (off time for main contactor) by counter 1 , and the ON hours (on time for main contactor) by counter 2 . Two counters are imitated for this purpose.

2- Accumulating the total shift times corresponding to two counters outputs (the sum of ON and OFF times).

3- Saving all shifts time through memory saving system, which can display and print the guard shift times (e.g. daily/weekly/monthly with his name).

4- By analysing the memory system by financial man (management), he can calculate the total worked hours for any night guard (e.g. three guard shifts with three address 1, 2, and 3). In case of any difference in counters, e.g. standard programming system with; counter $1=7$ hours and Counter $2=1$ hours, the official guard will be contraventions of inferiority from his salary.

A summary of the functions of the main proposed power savings system is explained through Table 3. Fig. 1 shows schematic operation of proposed power saving system and Fig. 2 shows the final proposed saving power circuit. This figure demonstrates that counter 1 refers to starting the shift time for the guard, e.g. in each new shift, the guard must push this button to start his time work, and counter 2 refers to the start of operation of power, ON for contactor. The output data saved on the screen indicates that the shift time is ended.

There are two input powers for the circuit: the first from PC, and the second from adaptor (220/9V DC) or rechargeable battery. The SD memory system is to save the monthly shifts. There is an outer used circuit through the operation of relay (ON/OFF), it can input any power (220/380 V Ac or Dc) and output this value to any electrical component (motor, contactor, ...etc.).

\section{B) Cost saving representation}

The developed equations for the proposed saving procedure are presented through Equations 1-5. The total consumed power and the related accompanied economic benefits can be expressed as follows:

$$
P_{\text {sh } 1}=\frac{K}{100} P_{T}
$$

where,

$P_{s h 1}:$ Consumedpower "GWhr" During8 AM : 4 PM shift (8 hours)

$\mathrm{P}_{\mathrm{T}}$ : Total consumedpower "GWhr" During 24 hours (6292GWhr)

K :percentageconsumedpower from $80 \%$ to $30 \%$ by step $10 \%$ (from total consumedpower)

$$
\begin{aligned}
& P_{\mathrm{sh} 2}=P_{T}\left[1-\frac{K}{100}\right] \\
& S P=\frac{F}{100} P_{\text {sh } 2}
\end{aligned}
$$

where, 
$P_{s h 2}:$ Consumedpower" GWhr" During 4 PM : 8 AM shift(16 hours)

SP :Saving power during 4 PM: 8 AM shift(16 hours),by propos edcircuit

F :Percentage saving factor from $10 \%$ to $80 \%$ by step $10 \%$ (from total consumedpower)

$$
C_{s h 1}=0.72 * \mathrm{P}_{\mathrm{sh} 1} * 10^{6}
$$

where:

$\mathrm{C}_{\mathrm{sh} 1}$ :Total costs of consumedpower "GWhr" during $8 \mathrm{AM}: 4 \mathrm{PM}$ shift (8 hours)by egyptian pounds

0.72 :Nearly average tarrif value "pound/kWh" according to Egyptian Ministry of electricaland Energy "usedenergy low voltage,380 V" [29]

$$
S C_{s h 1}=0.72 * S P * 10^{6}
$$

where:-

$$
\begin{aligned}
& 0.72 \text { : Nearly average tarrif value "pound/kWh" according to Egyptian Ministry of electricaland Energy } \\
& \text { "usedenergy low voltage,380 V" [29] } \\
& S P \text { :Saving power "GWhr" during } 4 \mathrm{PM}: 8 \mathrm{AM} \text { shift(16 hours),by proposedcircuit } \\
& S C_{\mathrm{sh} 2} \text { : Saving moneyby usingproposedcircuit, Egptianpounds }
\end{aligned}
$$

\section{Assessment OF The Proposed Power Saving System}

According to the reported data of the ministry of electricity in Egypt through the year (2015-2016) [28], the governmental institutions consumed powers equal $6292 \mathrm{GWH}$ which represents $4.05 \%$ from the total consumed powers. There is a large amount of consumed electrical power through lighting and other applications during day (fan, air condition...etc.). The periods of non-daily work (4 PM-8AM) in the Governmental institutions (Ministries, Schools, governmental buildings....etc.) are controlled by night guard, who do not have sufficient awareness about the importance of saving electrical power. To assess the proposed saving system, the working day is divided into two timing shifts. The first shift is considered as the effective working period (from 8 AM- 4 PM). While the second shift starts from 4 PM to the morning of the next day (8 AM). It was worth to control the unusual consumed energy by the proposed smart model through the second shifts (4 PM- $8 \mathrm{AM})$.

Table 4 presents various consumed power through daily useful/unusual power according to equations 1-3. The economic analysis of consumed energy, depending on proposed method according to Equations 4 and 5, is presented in Table 5 considering the tariff of energy during the year (2015-2016) with an average of 0.72 pound $/ \mathrm{kWh}$. Table 5 shows the economic benefits in million pounds during year 2015-2016 by using proposed method with $80 \%$ consumed power during 8 AM: 4 PM and $20 \%$ of total consumed power during 4 PM: 8 AM "saving index F from 10 to $80 \%$ of shift 4 PM: 8 AM".

\section{Conclusions}

The proposed power saving system can control the operation time of electrical power system in any building according to time management table through unworked shifts (4 PM : 8 AM). It can decide the work time and the operation time of electricity during any shift ( except the emergency loads). It can save from $125.84 \mathrm{GWh}(0.081 \%$ of total 
consuming energy) as a minimum value up to about $3523.52 \mathrm{GWh}(2.268 \%$ of total consuming energy) in Egyptian government buildings (Table 4). When it is applied to other loads (e.g. houses loads) with the only $10 \%$ saving as assumption, it can save more energy between $1.029 \%$ to $3.2126 \%$ which are effective values. The smart power saving system can save 90.6048 million pounds, as a minimum value, to about 2536.9 million pounds yearly (this saving money can be increased if used average commercial tariff , which is about 0.72 pound for each $\mathrm{KWh}$ as average value according to Egyptian ministry of electricity ships). It can also be integrated in any application, e.g. government buildings, factories, etc. The proposed system can be extended to other consumed loads such as houses, industrial,...etc. and thus, this method will save a large amount of energy. For a saving of $1 \%$ in consumed houses energy, the saving energy by this method will reach about $7336.1 \mathrm{GWh}$, which means that the total saved energy after adding this amount to the saved government buildings will be in the range from $1.081 \%$ to $3.268 \%$ of the total consumed energy in Egypt.

One of the main merits of the proposed smart saving system is the design simplicity and its high effectiveness for energy saving with low implementation cost and high efficiency. Added to that, the main advantages of the proposed smart system in comparison with the existing methods ( detailed in section I) are the low cost of its implementation and the highest savings of power consumption levels. Also, it may be implemented for old buildings without any special needs of additional electrical installation.

\section{References}

[1] Jong-Hoon Lee, Jung-Tae Kim, Eui-Hyun Paik, Intark Han, and Kwang-Roh Park. " Design and implementation of a service oriented power saving system for the home network." 2009 Digest of Technical Papers International Conference on Consumer Electronics, IEEE, 2009.

[2] Yen Kheng Tan, Truc Phuong Huynh, and Zizhen Wang. " Smart personal sensor network control for energy saving in DC grid powered LED lighting system." IEEE Transactions on smart grid 4.2,PP. 669-676, 2013.

[3] Byun, Jinsung, et al. "Design and implementation of an Intelligent energy saving system based on standby power reduction for a future zero-energy home environment." IEEE Transactions on Consumer Electronics 59.3, pp. 507-514, 2013.

[4] S. Prasanna, et al."Automated Intelligent Power Saving System and Security System", Advance in Electronic and Electric Engineering $\odot$ Research India Publications, 3.9, pp. 1167-1176, 2013.

[5] Sunil Kumar.Matangi, and Sateesh.Prathapani " Design of Smart Power Controlling and Saving System in Auditorium by using MCS 51 Microcontrollers." Advanced Engineering and Applied Sciences: An International Journal, 3.1, pp. 5-9, 2013.

[6] Sugawara, Mayuko, Toshihiro Taketa, and Yukio Hiranaka. "Power-saving system which distributes saving target among electrical appliances." The 1st IEEE Global Conference on Consumer Electronics 2012, pp. 251-255, 2012.

[7] Chanda, S., et al. "Implementation of non-intrusive energy saving estimation for Volt/VAr control of smart distribution system." Elsevier, Electric Power Systems Research 120, pp.39-46, 2015. 
[8] Kim, So-Hyun, et al. "Evaluation of optimized PV power generation and electrical lighting energy savings from the PV blind-integrated daylight responsive dimming system using LED lighting." Elsevier, Solar Energy 107, pp. 746-757, 2014.

[9] Gentile, Niko, Thorbjörn Laike, and Marie-Claude Dubois. "Lighting control systems in peripheral offices rooms at high latitude: measurements of electricity savings and users preferences" Elsevier, Energy Procedia 57, pp. 1987-1996, 2014.

[10] Niko Gentile, Thorbjörn Laike, and Marie-Claude Dubois. "Lighting control systems in individual offices rooms at high latitude: Measurements of electricity savings and occupants' satisfaction" Elsevier, Solar Energy 127, pp.113-123, 2016.

[11] Boyano, A., P. Hernandez, and O. Wolf. "Energy demands and potential savings in European office buildings: Case studies based on Energy Plus simulations." Elsevier, Energy and Buildings 65, pp.19-28, 2013.

[12] Han, $\mathrm{Xu}$, et al. "Multi-objective building energy consumption prediction and optimization for eco-community planning "Elsevier, Energy and Buildings 66 , pp. 22-32, 2013.

[13] Zhao, Liang, Ji-li Zhang, and Ruo-bing Liang. "Development of an energy monitoring system for large public buildings." Elsevier, Energy and Buildings 66 , pp. 41-48, 2013.

[14] Vagelis Vossos, Karina Garbesi, and Hongxia Shen. "Energy savings from directDC in US residential buildings." Elsevier, Energy and Buildings 68 , pp. 223-231, 2014.

[15] Andreas Thewes, et al. "Field study on the energy consumption of school buildings in Luxembourg" Elsevier, Energy and Buildings 68 (2014): 460-470.

[16] S. Y. Lin, S.-C. Chiu, W-Y. Chen. "Simple automatic supervisory control system for office building based on energy-saving decoupling indoor comfort control." Elsevier, Energy and Buildings 86, pp. 7-15, 2015.

[17] J. Z. Thellufsen, H. Lund. "Energy saving synergies in national energy systems." Elsevier, Energy Conversion and Management 103 , pp.259-265, 2015.

[18] N. A. Muhamada, Lee Yun Phinga, Y. Z. Arief. "Pre-study on potential electrical energy savings in Malaysia dairy manufacturing industry of medium enterprises" Elsevier, 2nd International Conference on Sustainable Energy Engineering and Application, ICSEEA 2014, Energy Procedia 68, pp. 205 - 218, 2015.

[19] P.Chiradeja, , A. Ngaopitakkul, and C. Jettanasen. "Energy savings analysis and harmonics reduction for the electronic ballast of T5 fluorescent lamp in a building's lighting system." Elsevier, Energy and Buildings 97 ,pp. 107-117, 2015.

[20] R. Kralikova, M. Andrejiova, and E. Wessely. "Energy saving techniques and strategies for illumination in Industry" Elsevier, Procedia Engineering 100 pp. 187195, 2015.

[21] E. J. Gago, et al. "Natural light controls and guides in buildings. Energy saving for electrical lighting, reduction of cooling load" Elsevier, Renewable and Sustainable Energy Reviews 41, pp.1-13, 2015.

[22] S. Petcharat, S. Chungpaibulpatana, and P.Rakkwamsuk, "Assessment of potential energy saving using cluster analysis: A case study of lighting systems in buildings." Elsevier, Energy and Buildings 52,pp. 145-152, 2012.

[23] N. Luewarasirikul, "A Study of Electrical Energy Saving in Office," Elsevier, Procedia-Social and Behavioral Sciences 197, pp.1203-1208, 2015. 
[24] Mehta, V. K., and R. Mehta. Principles of power systems. Vol. 15. S. Chand, New Delhi, 1982.

[25] Pérez-Lombard, Luis, José Ortiz, and Christine Pout. "A review on buildings energy consumption information." Elsevier, Energy and buildings 40.3, pp. 394-398, 2008.

[26] Janda, Kathryn B., and John F. Busch. "Worldwide status of energy standards for buildings." Energy 19.1, pp.27-44, 1994.

[27] Laustsen, Jens. "Energy efficiency requirements in building codes, energy efficiency policies for new buildings." International Energy Agency (IEA), pp. 477488, 2008.

[28] Electrical reports of Egypt 2015-2016: egyptera.org/ar/elec_report.aspx

[29] www.egyptera.org

[30] UN Climate Change Conference Doha Nove 
Table 1. The Power consumed through years 2005-2016 in Egypt with relative variations [29].

\begin{tabular}{|c|c|c|c|}
\hline Years & $\begin{array}{c}\text { Consumed } \\
\text { power } \\
\text { (GWh) }\end{array}$ & $\begin{array}{c}\text { annual } \\
\text { percentage } \\
\text { increase }(\%)\end{array}$ & $\begin{array}{c}\text { Cumulative change } \\
\text { from year 2005-2006 } \\
(\%)\end{array}$ \\
\hline $2005-2006$ & 92085 & -- & -- \\
\hline $2006-2007$ & 98443 & 6.9 & 6.9 \\
\hline $2007-2008$ & 106595 & 8.28 & 15.76 \\
\hline $2008-2009$ & 111714 & 4.8 & 21.32 \\
\hline $2009-2010$ & 118903 & 6.44 & 29.12 \\
\hline $2010-2011$ & 125159 & 5.26 & 35.92 \\
\hline $2011-2012$ & 133969 & 7.04 & 45.48 \\
\hline $2012-2013$ & 140257 & 4.69 & 52.31 \\
\hline $2013-2014$ & 142935 & 1.91 & 55.22 \\
\hline $2015-2016$ & 155318 & 6.42 & 68.67 \\
\hline
\end{tabular}

Table 2. Distribution of consumed power according to applications

\begin{tabular}{|c|c|c|c|c|}
\hline \multirow[t]{2}{*}{ Application } & \multirow{2}{*}{$\begin{array}{c}\text { 2013-2014, } \\
\text { GWH }\end{array}$} & \multirow{2}{*}{$\begin{array}{c}\text { 2014-2015, } \\
\text { GWH }\end{array}$} & \multicolumn{2}{|c|}{ 2015-2016, } \\
\hline & & & GWH & $\begin{array}{c}\text { Variations \% from } \\
2014-2015 \\
\end{array}$ \\
\hline Industrial & 3732 & 38242 & 38310 & 0.18 \\
\hline Agriculture & 6517 & 6555 & 6755 & 3.05 \\
\hline General usages & 5692 & 6338 & 6519 & 2.86 \\
\hline General lighting & 5692 & 5353 & 5293 & 1.12 \\
\hline $\begin{array}{l}\text { Governmental } \\
\text { Institutions }\end{array}$ & 8090 & 6062 & 6292 & 3.79 \\
\hline Domestics " housing" & 61962 & 64546 & 73361 & 13.66 \\
\hline Souvenir and others & 17392 & 18850 & 18788 & 0.33 \\
\hline $\begin{array}{l}\text { Total consumed } \\
\text { power }\end{array}$ & 142935 & 145946 & 155318 & 6.42 \\
\hline
\end{tabular}

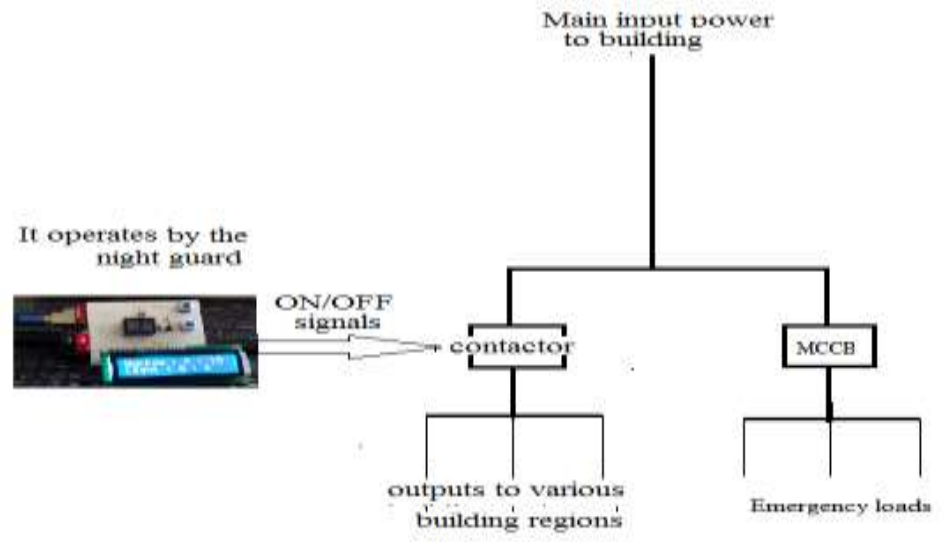


Fig. 1. The operation of proposed power saving system

Table 3. Features and specification of the proposed power saving system components

\begin{tabular}{|l|l|l|}
\hline $\begin{array}{l}\text { Component } \\
\text { Name }\end{array}$ & \multicolumn{3}{|c|}{ Features } \\
\hline Arduino board & $\begin{array}{l}\text { It is an open hardware microcontroller board, which is based on } \\
\text { ATmega328 from Atmel company to develop a lot of ideas and } \\
\text { projects related to automatic control in simple way by using of open } \\
\text { hardware programming language Arduino Integrated Development } \\
\text { Environment (Arduino IDE). It can be powered via the USB } \\
\text { connection or with an external power supply (the power source is } \\
\text { selected automatically). }\end{array}$ \\
\hline $\begin{array}{l}\text { SD System } \\
\text { shield }\end{array}$ & $\begin{array}{l}\text { The communication between the microcontroller and the SD system } \\
\text { uses SPI interface, which takes place on digital pins 11, 12, and 13 } \\
\text { (on most Arduino boards). Additionally, another pin must be used to } \\
\text { select the SD system. This can be the hardware SS pin - pin 10 (on } \\
\text { most Arduino boards) or another pin specified in the call to SD. }\end{array}$ \\
\hline $\begin{array}{l}\text { LCD 1602 } \\
\text { Transflective Dot Matrix LCD module, the connector: 16 pins ZIF } \\
\text { SMD connector (CON-IL-402) and HD44780 LCD Controller and } \\
\text { Driver or equivalent. }\end{array}$ \\
\hline $\begin{array}{l}\text { Relay SPDT } \\
\text { Sealed }\end{array}$ & $\begin{array}{l}\text { These are high quality Single Pole - Double Throw (SPDT) fully } \\
\text { sealed relays. They are used to switch high voltage, and/or high } \\
\text { current devices. This relay's coil is rated up to 12V, with a minimum } \\
\text { switching voltage of 5V DC. The contacts currents are rated up to 5A. }\end{array}$ \\
\hline $\begin{array}{l}\text { Transistor } \\
\text { STese are very common, high quality BJT NPN transistors made by }\end{array}$ \\
\hline ST Micro.
\end{tabular}

* SRAM refers to Static Random Access Memory 


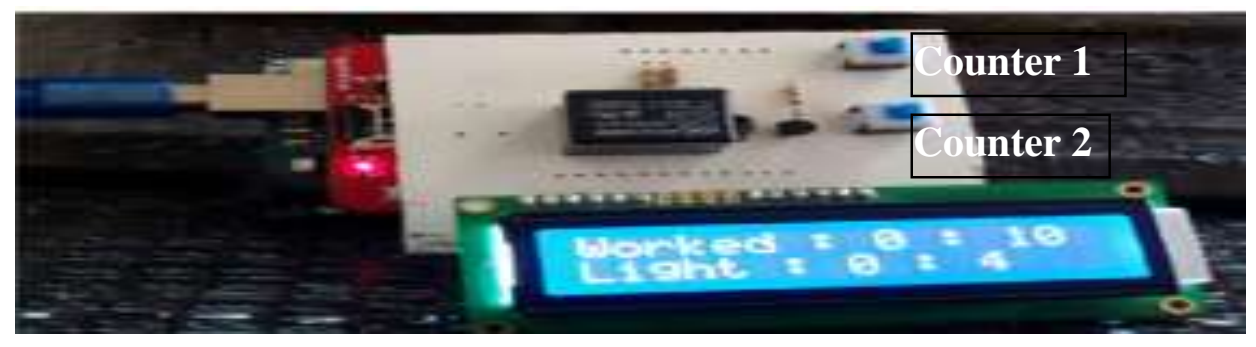

Fig. 2. Final power saving circuit

Table 4. Power consumed and the corresponding power saving by proposed technique

\begin{tabular}{|c|c|c|c|c|c|c|c|c|}
\hline \multirow{3}{*}{$\begin{array}{c}\text { Proposed Power } \\
\text { consumed during } \\
\text { the working shift } \\
\text { (8 Am: } 4 \text { PM) } \\
\text { GWh," } P_{\text {sh1 }}\end{array}$} & \multicolumn{8}{|c|}{$\begin{array}{c}\text { Proposed Saving Power during the period ( } 4 \text { PM : } 8 \text { AM) GWh, } \\
\text { "SP" }\end{array}$} \\
\hline & \multicolumn{8}{|c|}{ F : Saving factor } \\
\hline & $10 \%$ & $20 \%$ & $30 \%$ & $40 \%$ & $50 \%$ & $60 \%$ & $70 \%$ & $80 \%$ \\
\hline $80 \%(5033.6)$ & 125.84 & $\begin{array}{c}251.6 \\
8\end{array}$ & $\begin{array}{c}377.5 \\
2\end{array}$ & 503.36 & 629.2 & $\begin{array}{c}755.0 \\
4\end{array}$ & $\begin{array}{c}880.8 \\
8\end{array}$ & $\begin{array}{c}1006 . \\
72\end{array}$ \\
\hline$\overline{404.4)}$ & 188.76 & $\begin{array}{c}377.5 \\
2\end{array}$ & $\begin{array}{c}566.2 \\
8\end{array}$ & 755.04 & 943.8 & $\begin{array}{c}1132 . \\
56\end{array}$ & $\begin{array}{c}1321 . \\
32\end{array}$ & $\begin{array}{c}1510 . \\
08\end{array}$ \\
\hline $60 \%$ (3775.2) & 251.68 & $\begin{array}{c}503.3 \\
6\end{array}$ & $\begin{array}{c}755.0 \\
4\end{array}$ & $\begin{array}{c}1006.7 \\
2\end{array}$ & $\begin{array}{c}1258 . \\
4\end{array}$ & $\begin{array}{c}1510 . \\
08\end{array}$ & $\begin{array}{c}1761 . \\
76\end{array}$ & $\begin{array}{c}2013 . \\
44\end{array}$ \\
\hline $50 \%(3146)$ & 314.5 & 629.2 & 943.8 & 1258.4 & $\begin{array}{c}1572 . \\
5\end{array}$ & 1887 & $\begin{array}{c}2201 . \\
5\end{array}$ & 2516 \\
\hline $40 \%(2516.8)$ & 377.52 & $\begin{array}{c}755.0 \\
4\end{array}$ & $\begin{array}{c}1132 . \\
5\end{array}$ & $\begin{array}{l}1510.0 \\
8\end{array}$ & $\begin{array}{c}1887 . \\
6\end{array}$ & $\begin{array}{c}2265 . \\
12\end{array}$ & $\begin{array}{c}2642 . \\
64\end{array}$ & $\begin{array}{c}3020 . \\
16\end{array}$ \\
\hline $30 \%(1887.6)$ & 440.44 & $\begin{array}{c}880.8 \\
8\end{array}$ & $\begin{array}{c}1321 . \\
3\end{array}$ & $\begin{array}{c}1761.7 \\
6\end{array}$ & $\begin{array}{c}2202 . \\
2\end{array}$ & $\begin{array}{c}2642 . \\
64\end{array}$ & $\begin{array}{c}3083 . \\
08\end{array}$ & $\begin{array}{c}3523 . \\
52\end{array}$ \\
\hline
\end{tabular}


Table 5. Saving money by using proposed method (million pounds/year)

\begin{tabular}{|c|c|c|c|c|c|c|c|c|}
\hline \multirow{3}{*}{$\begin{array}{l}\text { Proposed consumed } \\
\text { power costs ( } 8 \mathrm{AM}: 4 \\
\text { PM) in million } \\
\text { pounds/Year, " } C_{\text {sh1 }} "\end{array}$} & \multicolumn{8}{|c|}{$\begin{array}{l}\text { Proposed Saving costs in million pounds during ( 4PM:8AM)/Year, } \\
\qquad S_{\mathrm{sh} 2} \text { " }\end{array}$} \\
\hline & \multicolumn{8}{|c|}{$\mathrm{F}$ : Saving factor } \\
\hline & $10 \%$ & $20 \%$ & $30 \%$ & $40 \%$ & $50 \%$ & $60 \%$ & $70 \%$ & $80 \%$ \\
\hline $80 \%, 3624.192$ & $\begin{array}{l}90 . \\
8\end{array}$ & $\begin{array}{l}181.20 \\
96\end{array}$ & $\begin{array}{l}271.81 \\
44\end{array}$ & $\begin{array}{l}362 . \\
41\end{array}$ & $\begin{array}{l}453.02 \\
4\end{array}$ & $\begin{array}{l}54 \\
2\end{array}$ & $\begin{array}{l}634.2 \\
33\end{array}$ & $\begin{array}{l}724.8 \\
3\end{array}$ \\
\hline $70 \%, 31$ & & $\begin{array}{l}271.81 \\
44\end{array}$ & & $\begin{array}{l}543 . \\
62\end{array}$ & $\begin{array}{l}679.53 \\
6\end{array}$ & $\begin{array}{l}815.4 \\
4\end{array}$ & $\begin{array}{l}951.3 \\
50\end{array}$ & $\begin{array}{l}1087 . \\
2\end{array}$ \\
\hline $60 \%, 2$ & & & $\begin{array}{l}543.62 \\
88\end{array}$ & $\begin{array}{l}724 . \\
83\end{array}$ & $\begin{array}{l}906.04 \\
8\end{array}$ & $\begin{array}{l}1087 . \\
2\end{array}$ & $\begin{array}{l}1268 \\
46\end{array}$ & $\begin{array}{l}1449 . \\
6\end{array}$ \\
\hline $50 \%, 2265$ & 226.44 & 452.88 & 679.32 & $\begin{array}{l}905 . \\
76\end{array}$ & 1132.2 & $\begin{array}{l}1358 . \\
6\end{array}$ & $\begin{array}{l}1585 . \\
08\end{array}$ & $\begin{array}{l}1811 . \\
5\end{array}$ \\
\hline $40 \%, 1812$ & $\begin{array}{l}271.72 \\
8\end{array}$ & $\begin{array}{l}543.45 \\
6\end{array}$ & 18 & $\begin{array}{l}1086 \\
.9\end{array}$ & $\begin{array}{l}1358.6 \\
4\end{array}$ & $\begin{array}{l}1630 . \\
3\end{array}$ & $\begin{array}{l}1902 . \\
09\end{array}$ & $\begin{array}{l}2173 . \\
8\end{array}$ \\
\hline $30 \%$ & $\begin{array}{l}317.11 \\
68\end{array}$ & $\begin{array}{l}634.23 \\
36\end{array}$ & $\begin{array}{l}951.35 \\
04\end{array}$ & $\begin{array}{l}1268 \\
.4\end{array}$ & $\begin{array}{l}1585.5 \\
84\end{array}$ & $\begin{array}{l}1902 . \\
7\end{array}$ & $\begin{array}{l}2219 . \\
81\end{array}$ & $\begin{array}{l}2536 . \\
9\end{array}$ \\
\hline
\end{tabular}

